\title{
O PROBLEMA DA RELAÇÃO ESTRUTURA/ AGENCIA NA TEORIA SOCIAL E A POSSIBILIDADE DE CONVERGENCIA ENTRE HABERMAS E BOURDIEU
}

\author{
Júlio Roberto de Souza Pinto*
}

\begin{abstract}
RESUMO: Este trabalho procura demonstrar que Jürgen Habermas e Pierre Bourdieu, cada um a sua maneira e de diferentes pontos de partida, construíram perspectivas teórico-metodológicas convergentes, de acordo com as quais a referência ontológica fundamental para a investigação das entidades e processos constitutivos da vida societária não é qualquer forma de totalidade coletiva concebida de modo reificado nem a experiência subjetiva do ator individual, mas as interações e as práticas sociais desenroladas em contextos sócio-históricos definidos, concebidas, umas e outras, como locus fundamental de entrelaçamento entre as dimensões objetivas e subjetivas do universo societário.
\end{abstract}

PALAVRAS-CHAVE: Estrutura; Agência; Habermas; Bourdieu; Perspectivas TeóricoMetodológicas Convergentes.

ABSTRACT: This paper seeks to show that Jürgen Habermas and Pierre Bourdieu, each in their own way and from different starting points, built convergent theoretical and

\footnotetext{
* Doutor em Sociologia pela Universidade de Brasília, mestre em Liberal Arts por Wheaton College (Illinois, EUA), especialista em Direito Legislativo pela Universidade do Legislativo (Senado Federal, Brasília-DF)/Universidade Federal do Mato Grosso do Sul e em Educaçãopela Universidade Mackenzie (São Paulo-SP). Assessor jurídico, pesquisador e professor da Câmara dos Deputados. Autor dos livros Poder Legislativo Brasileiro: institutos e processos (Rio de Janeiro: Forense, 2009) e Sistema político e comportamento parlamentar (Brasília: Consulex, 2011) e um dos organizadores dos livros Estudos legislativos: pensamento e ação política (Brasília: Câmara dos Deputados, Senado Federal e Universidade de Brasília, 2008) e Estudos legislativos: 20 anos da Constituição Brasileira (Brasília: Câmara dos Deputados, Senado Federal e Universidade de Brasília, 2010).
} 
methodological perspectives, according to which the fundamental ontological reference for the investigation of entities and processes that constitute social life is not any form of collective whole designed in a reified way nor the subjective experience of the individual actor, but the interactions and social practices developed in defined socio-historical contexts, designed as fundamental locus of entanglement between the objective and subjective dimensions of the social universe.

KEYWORDS: Structure; Agency; Habermas; Bourdieu; Convergent Theoretical and Methodological Perspectives.

\section{INTRODUÇÃO}

À medida que um dos pólos do dualismo estrutura/agência é tomado como elemento explicativo do outro, o pensamento social clássico e contemporâneo pode ser, grosso modo, dividido em dois conjuntos de perspectivas teóricas: dum lado, o conjunto de enfoques objetivistas e holistas, que, a despeito de discordarem sobre questões como a importância do consenso ou do conflito no fluxo da vida social, centram sua análise nas coerções exercidas pelas estruturas sociais sobre a conduta dos atores individuais, caracterizando as propriedades de tais arranjos sociais como operando à revelia da vontade dos indivíduos; doutro lado, o conjunto de abordagens subjetivistas e individualistas, que focam nas diversas orientações subjetivas e procedimentos práticos de conduta intencionalmente mobilizados pelos indivíduos na produção da ação e da interação social, concebendo a ordem societária e suas instituições mais amplas como produtos contínuos e contingencialmente modificáveis das ações de tais agentes reflexivos.

Ainda arriscando incorrer em grosseira generalização e simplificação, entre as perspectivas mais próximas ao enfoque objetivista, poderiam ser citados a sociologia de Émile Durkheim, o estrutural-funcionalismo radical da última fase da obra de Talcott Parsons, a abordagem teórico-sistêmica de Niklas Luhmann, a antropologia estruturalista de Claude Lévi-Strauss e as diversas interpretações determinísticas do marxismo, como a de Louis Althusser. Entre as perspectivas mais próximas ao enfoque subjetivista, por sua vez, poderiam ser mencionados o interacionismo simbólico de George Herbert Mead e de 
Herbert Blumer, a microssociologia dramatúrgica de Erving Goffman, a fenomenologia social de Alfred Schutz, a etnometodologia de Harold Garfinkel, as filosofias neo-wittgensteinianas da ação social e, com maiores reservas, a teoria da escolha racional. ${ }^{1}$

Essa polarização dicotômica, entretanto, tem causado enormes prejuízos ao desenvolvimento da teoria social. Jürgen Habermas e Pierre Bourdieu, entre outros cientistas sociais contemporâneos, ${ }^{2}$ notadamente nas respectivas obras On the logic of the social science (1988) ${ }^{3}$ e Science de la science et réflexivité (2001), procuram articular, cada um a sua maneira, o plano das estruturas coletivas, isto é, dos padrões institucionalizados de conduta ou de relações que atuam coercitivamente sobre a formação/socialização e sobre a contínua ação dos agentes individuais, estendendo-se pelas coordenadas espaço-temporais mais amplas que conformam grupos ou sociedades inteiras e transcendendo as

${ }^{1}$ É claro que, se qualquer tentativa de dividir o pensamento social clássico e contemporâneo em dois grandes conjuntos de perspectivas teóricas em relação às dicotomias estrutura/agência, objetivismo/subjetivismo, holismo/individualismo já incorre no risco de grosseira generalização e simplificação, o perigo é maior quando se tenta classificar, ainda que por aproximação, o conjunto dos trabalhos de cientistas sociais nesses dois grandes conjuntos. O problema é complexificado ainda mais pelo fato de tais antinomias referirem-se tanto a caracterizações ontológicas abstratas da vida social quanto à construção de esquemas metodológicos de explicação dos fenômenos societários. A controvérsia em torno das abordagens alternativas do holismo e do individualismo metodológicos, por exemplo, conquanto envolva argumentos de caráter ontológico, é mais propriamente considerada como um confronto entre lógicas explanatórias diferentes. Enquanto o dualismo holismo/individualismo insere-se de modo mais evidente no debate sobre o status explanatório de fatores coletivos e da ação individual como variáveis da estrutura da explicação sociológica, as dicotomias estrutura/agência e objetivismo/subjetivismo acomodam-se melhor na descrição de diferentes ontologias da vida social. Referem-se à necessidade de se tratar da relação de contínua influência recíproca ou interdependência causal entre formações coletivas e ações individuais no curso do devir histórico. ${ }^{2}$ Tais como Anthony Giddens.

${ }^{3}$ Esse trabalho originalmente apareceu em alemão como um volume suplementar especial do jornal Philosophische Rundschau em fevereiro de 1967. Foi publicado na forma de livro sob o título Zur Logik der Sozialwissenschaften em 1970. 
existências individuais, com o plano da ação, ou seja, da conduta individual cotidiana e de seus motores subjetivos.

Habermas e Bourdieu, em suas tentativas de superação dessas antinomias inter-relacionadas (estrutura/agência, objetivismo/subjetivismo, holismo/ individualismo), construíram, de diferentes pontos de partida, ${ }^{4}$ perspectivas teórico-metodológicas convergentes, de acordo com as quais a referência ontológica fundamental para a investigação das entidades e processos constitutivos da vida societária não é qualquer forma de totalidade coletiva concebida de modo reificado nem a experiência subjetiva do ator individual, mas as interações e as práticas sociais desenroladas em contextos sóciohistóricos definidos, concebidas, umas e outras, como locus fundamental de entrelaçamento entre as dimensões objetivas e subjetivas do universo societário.

Andreas Reckwitz (2002) situa Habermas e Bourdieu no que denomina de "modelo culturalista", caracterizando-o como um esquema de descrição e explicação da ação e da reprodução social baseado na reconstrução das estruturas simbólico-cognitivas socialmente aprendidas que orientam subjetivamente o comportamento dos agentes, e contrastando-o com o "modelo do homo sociologicus", segundo o qual a conduta individual é orientada por normas coletivamente compartilhadas que garantem a harmonização relacional das ações dos indivíduos, e com o "modelo do homo economicus", em conformidade com a qual o agente é essencialmente voltado à busca racional de interesses individuais, sendo a ordem social o resultado da combinação duma multitude de ações guiadas pelo auto-interesse. Reckwitz, contudo, localiza Habermas e Bourdieu em diferentes subcategorias culturalistas:

\footnotetext{
${ }^{4}$ Habermas construiu sua teoria da ação comunicativa a partir da exegese e crítica de diversas escolas de pensamento, ao passo que Bourdieu construiu sua "teoria da ação prática" no contínuo enfrentamento de problemas empíricos específicos de pesquisa, buscando refinar, por meio desse engajamento investigativo, as tradições de pensamento. Apesar de ambos buscar em superar os dualismos estrutura/ação, objetivismo/subjetivismo e holismo/individualismo, adotaram percursos intelectuais e modus operandi de elaboração teórica distintos.

${ }^{5}$ Giddens é situado na mesma subcategoria que Bourdieu. As outras subcategorias em que Reckwitz divide o modelo culturalista são o mentalismo e o textualismo.
} 
Habermas é situado no "culturalismo intersubjetivista", ao passo que Bourdieu, no "culturalismo praxiológico". ${ }^{5}$ Este trabalho mostrará, todavia, que tanto a teoria da prática de Bourdieu ${ }^{6}$ envolve intersubjetividade quanto a teoria da ação comunicativa de Habermas, ${ }^{7}$ práxis.

\section{JÜRGEN HABERMAS E ON THE LOGIC OF SOCIAL SCIENCE}

Em On the logic of social science, Habermas procura pôr as abordagens objetivista e subjetivista "under one roof", como Max Weber já havia tentado fazer. A propósito, cita a definição de sociologia que dá Weber no primeiro parágrafo de Economy and society, de acordo com a qual "sociology is a science concerning itself with the interpretative understanding of social action and thereby with a causal explanation of its course and consequences" (p. 10), para, em seguida, destacar o tratamento ambíguo dispensado por Weber ao assunto. Na visão habermasiana, Weber, de um lado, insistia na tarefa empíricoanalítica de explicar a ação social com a ajuda de hipóteses legaliformes acreditadas e de fazer prognósticos condicionados. À medida que o objeto o exija, essa análise pode vir mediada por uma compreensão do sentido das ações sociais. Mas essa intenção de entender o sentido que o agente subjetivamente atribui a sua ação só pode ter a finalidade de dar acesso aos fatos sociais, pois esses fatos sociais apenas são conhecidos quando a análise, indo além de tal "compreensão propedêutica", apreende os nexos legaliformes que os regem. A intenção hermenêutica de compreender o sentido tem, portanto, um status subordinado. Por outro lado, Weber, na perspectiva

\footnotetext{
${ }^{6}$ Bourdieu obviamente não considerava sua teoria da prática como uma "teoria teórica", isto é, como um discurso profético ou programático que tem em si mesmo seu próprio fim e que nasce e vive da defrontação com outras teorias. Antes, considerava-a como uma "teoria científica", ou seja, como um programa de percepção e de ação só revelado no trabalho empírico em que se realiza (BOURDIEU, 1989). Na prática, no entanto, algumas vezes utiliza suas ferramentas analíticas não apenas como peças dum vocabulário conceitual, mas também como princípios explanatórios universais, como é o caso, por exemplo, da relação campo/habitus.

7 The theory of the communicative action somente foi publicada em 1981, mais de uma década depois da obra habermasiana em análise neste ensaio.
} 
habermasiana, como um bom discípulo de Heinrich J. Rickert, não podia esgotar seu interesse na investigação de regularidades empíricas. Daí que não considerava a dedução e comprovação de hipóteses legaliformes, a partir das quais se possam obter recomendações técnicas, como trabalho prévio, que, como tal, não conduz ao "knowledge which we are seeking" (p. 13). Weber, porém, na avaliação habermasiana, falhou ao não pôr em conexão essas duas intenções cognitivas contrapostas. Para Habermas, essas "two conflicting cognitive intentions arise in the social sciences only because there the knowing subjects are intuitively linked with their object domain" (p. 14).

Com isso em mente, Habermas, ato contínuo, examina as abordagens funcionalistas, em particular o estrutural-funcionalismo de Talcott Parsons. Para ele, a visão parsoniana dos sistemas sociais como plexo funcional de instituições, incluída acima entre as abordagens que se aproximam do enfoque objetivista, enfrenta uma dificuldade de princípio: a identificação suficientemente confiável dum estado de equilíbrio. Segundo Habermas, a reprodução da vida social não vem fixada, como a reprodução na vida orgânica, por valores que possam ser apreendidos descritivamente, tampouco são encontradas, nos processos sociais, funções vitais que, como as funções orgânicas nos seres vivos, bastem para definir a conservação do sistema num estado de equilíbrio. Não existem valores de controle a priori; no máximo, eles podem ser politicamente construídos. Na avaliação habermasiana, a saída dessa dificuldade seria pela via duma "re-bistoricização da análise da sociedade" (p. 85). Em conformidade com o funcionalismo, os motivos da ação se harmonizam com os valores institucionais. Daí que as energias pulsionais não integradas não são apreendidas analiticamente. Habermas, porém, entende que essas necessidades reprimidas têm suas interpretações. Ou essas interpretações se disparam por cima do existente, designando, como antecipação utópica, uma identidade grupal ainda não alcançada, ou servem, trocadas em ideologias, tanto à justificação das instâncias repressoras das pulsações quanto a uma satisfação substitutiva de caráter projetivo. No entanto, se não se parte de infundados pressupostos harmonicistas, a ligação de energias pulsionais a regras e papéis está sempre associada também à repressão das necessidades interpretadas que não podem ser integradas nos papéis oferecidos. Assim, se tanto as interações plenas de sentido como as coações reativas 
motivam igualmente o comportamento, segue-se que a instituição dos valores deve ser entendida dialeticamente, sendo a ação social resultante de ambas. "The ration of action that is merely elicited by split-off motives to action that is intentionally guided by the communication of meaning determines the degree of freedom of the social action - the degree of flexibility of institutions and the degree of individuation of the individuals" (p. 88).

Em seguida, Habermas passa a tratar dos enfoques fenomenológico, linguístico e hermenêutico, inseridos acima entre as perspectivas que estão próximas à abordagem subjetivista e individualista. Na visão habermasiana, essas versões duma sociologia compreensiva estão tão preocupadas com o problema da adequada descrição das formas de comportamento mediadas simbolicamente que suas explicações da ação social vêm a coincidir com a aclaração compreensiva do sentido. Alfred Schutz, na perspectiva habermasiana, faz uma tentativa sistemática de extrair do marco rickertiano a colocação que faz Weber dos problemas básicos duma sociologia compreensiva e de situá-la no horizonte duma fenomenologia do mundo da vida estritamente vinculada a Edmund Husserl. Para Schutz, o mundo da vida se articula em plexos de significados culturalmente definidos e diferentemente distribuídos, os quais circunscrevem o campo de intencionalidade dentro do qual se orienta a ação social. Harold Gurfinkel, seu discípulo, vê as estruturas do mundo da vida como regras gerais de interpretação conforme as quais os agentes definem as situações cotidianas e se definem a si mesmos. Na perspectiva de Habermas, entretanto, numa linguagem muito parecida com a de Bourdieu, como se verá adiante,

we grasp the structure of individual lifeworlds only through communication experienced in a social context; ${ }^{8}$ one learns the specific rules of communication through systematic participation and not, as Schutz assumes, through phenomenological intuition or, as Cicourel and Garfinkel

\footnotetext{
${ }^{8}$ A versão espanhola, interessantemente, diz: "sólo podemos aprehender la estructura de los mundos individuales de la vida por vía de las comunicaciones convertidas socialmente en hábitos" (Madri: Tecnos, 2000, p. 199).
} 
assume, through phenomenologically guided experiments (...) The empirical conditions under which transcendental rules are formed and that establish the constitutive order of the lifeworld are themselves the result of the process of socialization. Thus I cannot see how these processes can be understood without reference to social norms. But if this is the case, the rules of interpretation can in principle not be distinguished from the rules of social action (...) Both are moments of the same social life-context (p. 113, 115-116).

Ainda na visão habermasiana, a análise lingüistica, como a fenomenológica, conduz à fundamentação duma sociologia compreensiva que estuda a ação social no plano da intersubjetividade. Mas a intersubjetividade não mais se estabelece pelo recíproco entrelaçamento de perspectivas virtualmente intercambiáveis dum mundo da vida. Antes, ela vem dada como as regras gramaticais das interações regidas por símbolos. Ludwig Wittgenstein, como representado por Habermas, entendia esses jogos de linguagem como um complexo de linguagem e práxis. Entender a linguagem remete a saber atuar, estando essa ação comunicativa ligada a expectativas simbolizadas de comportamentos. Em sua segunda fase, Wittgenstein não mais buscava descobrir uma linguagem universal que garantisse a exatidão, mas sim uma ordem imanente à linguagem natural. Na avaliação habermasiana, porém, Wittgenstein não conseguiu responder a questão do "jogo da metalinguagem" (p. 136): se todo enunciado só tem sentido no contexto de seu jogo de linguagem e se a análise lingüística torna os jogos de linguagem monádicos transparentes ao considerar suas semelhanças familiais, de que jogo de linguagem se serve essa análise? Para Habermas, o analista da linguagem, no papel de intérprete corporativo, tem de pressupor sempre um conceito de linguagem em geral e uma pré-compreensão concreta para a qual convirjam diferentes linguagens. $\mathrm{O}$ intérprete estabelece uma mediação entre padrões de socialização diferentes e, para efetuar essa tradução, apóia-se nos padrões em que ele mesmo foi socializado.

Com isso, Habermas introduz H. G. Gadamer e o campo da hermenêutica. Para Gadamer, na perspectiva habermasiana, as próprias línguas 
contêm um potencial duma razão que, expressando-se na particularidade duma gramática, empreende, ao mesmo tempo, uma reflexão sobre os limites dela e os nega como particulares. O horizonte duma língua abrange também o que ela não é. Daí que tampouco os limites do mundo que ela define sejam irrevogáveis. O enfrentamento do próprio com o estranho tem como conseqüência, quase sempre imperceptivelmente, revisões. A tradução é o meio pelo qual essas revisões se produzem. A hermenêutica conduz a um saber aplicativo que Gadamer explica recorrendo à definição aristotélica de saber prático: ele é reflexivo (um saber-se), internalizado (converte-se em parte da estrutura da personalidade) e global. $\mathrm{Na}$ avaliação habermasiana, no entanto,

an interpretative sociology that hypostatizes language as the subject of life forms and of tradition binds itself to the idealist presupposition that linguistically articulated consciousness determine the material being of life-practice. But the objective context of social action is not reducible to the dimensions of intersubjectively intended and symbolically transmitted meaning. The linguistic infrastructure is a moment in a complex that, however, symbolically mediated, is also constituted by the constraints of reality (...) The objective context in terms of which alone social actions can be understood is constituted conjointly by language, labor, and domination (pp. 258-259).

Por isso, conclui Habermas, a sociologia não pode ser reduzida a uma sociologia compreensiva. Ela exige um sistema de referência que, por um lado, não elimine, em termos naturalistas, a mediação simbólica da ação social, em favor dum comportamento simplesmente controlado por signos e governado por estímulos, mas que, por outro, tampouco caia no idealismo da lingüisticidade e sublime por inteiro os processos sociais a uma tradição cultural. Os limites duma sociologia compreensiva são os limites de seu próprio conceito de motivação: explica a ação social por motivos que coincidem com as interpretações que da situação fazem os próprios agentes. "If we insist nevertheless on an empirical-analytic understanding of the system, we must 
concern ourselves with communicative experience and accept a categorial framework that is in principle linked to the self-understanding of acting subjects and that can also be incorporated in turn into that self-understanding" ( $p$. 187). ${ }^{9}$

\section{PIERRE BOURDIEU E SCIENCE DE LA SCIENCE ET RÉFLEXIVITÉ}

Bourdieu, em Science de la science et réflexivité (2001), dá pouca atenção às perspectivas objetivistas ou, como ele aqui chama, "logicistas". ${ }^{10}$ Para ele, a tradição estrutural-funcionalista da sociologia da ciência rompeu com a visão oficial das epistemologias americanas: ela leva em conta o aspecto contingente da prática científica. Robert Merton e seus discípulos propuseram uma descrição coerente da ciência que se caracteriza, segundo eles, pelo universalismo, o comunismo ou comunalismo, o desinteresse e o ceticismo organizado. Essa abordagem, porém, não faz a menor referência a como os processos científicos são regulados. Antes, aceita a definição dominante, logicista, da ciência.

Nesse quadro, avalia Bourdieu, a principal contribuição de Thomas Kuhn foi mostrar que o desenvolvimento da ciência não é um processo contínuo, mas um processo marcado por uma série de rupturas e pela alternância de períodos de "ciência normal" e de "revoluções". Com isso, ele introduziu na tradição anglo-saxônica uma filosofia descontinuísta da evolução científica em ruptura com a filosofia positivista, que considerava a ciência como um movimento de acumulação contínua. Além disso, ele elaborou a idéia de "comunidade científica", de acordo com a qual os cientistas formam

\footnotetext{
${ }^{9} \mathrm{Na}$ versão espanhola: "Si pese a todo, queremos atenernos a una aprehensión empíricoanalítica del sistema social, habremos de recurrir a la experiencia comunicativa y hacer todo uso de un marco categorial que en principio conecte con la autocomprensión de los sujetos agentes y a la vez proporcione medios con que penetrarla reflexivamente" (p. 273).

${ }^{10}$ Bourdieu volta seu foco sobretudo na direção das abordagens subjetivistas ou "relativistas". Lembre-se que publicou esta obra após o declínio do positivismo e a ascendência do interpretativismo. A crítica bourdieusiana ao objetivismo é mais bem desenvolvida em obras como Les sens pratique (1980).
} 
uma comunidade fechada cuja pesquisa tem por objeto um leque bem definido de problemas e que utiliza métodos adaptados a esse trabalho. As ações dos estudiosos nas ciências avançadas são determinadas por um "paradigma" ou "matriz disciplinar", é dizer, um estado de realização científica que é aceita por uma fração importante dos estudiosos e que tende a se impor sobre todos os outros. Em que pese a haver chamado a atenção para as rupturas, para as revoluções, a descrição quase durkheimiana que faz Kuhn do mundo científico como uma comunidade dominada por uma norma central não convenceu Bourdieu de que tenha ele proposto um modelo coerente de explicação da mudança. Tal modelo, todavia, pode ser construído a partir duma leitura "particularmente generosa" do conflito interno entre a ortodoxia e a heresia, entre os defensores do paradigma e os inovadores. Bourdieu, de fato, surpreendentemente reconheceu dever a Kuhn, por meio dessa reinterpretação, a essência de sua representação da lógica do campo e de sua dinâmica: 'J'ai conscience d'avoir à Kubn, à travers cette réinterpretation, l'essence de ma répresentation de la logique du champ et de sa dynamique” (p. 36). Kuhn, que nunca teve nada de revolucionário, foi adotado, um pouco a contragosto, como um profeta por seus alunos da Universidade de Columbia e integrado ao movimento da "contracultura", que rejeitava a "racionalidade científica" e reivindicava a imaginação contra a razão.

Nessa esteira, continua Bourdieu, David Bloom se apóia em Wittgenstein para fundar uma teoria da ciência em conformidade com a qual a racionalidade, a objetividade e a verdade são normas socioculturais locais, são convenções adotadas e impostas por grupos particulares. Para Barry Barnes, na visão bourdieusiana, os interesses sociais suscitam as táticas de persuasão, as estratégias oportunistas e as disposições culturalmente transmitidas que influenciam o conteúdo e o desenvolvimento do conhecimento científico. Bourdieu atribui a Harry Collins o mérito de lembrar que o fato é uma construção coletiva e que é na interação entre aquele que produz o fato e aquele que o recebe e tenta replicá-lo, falsificandoo ou confirmando-o, que se constrói o fato atestado, certificado. Na avaliação de Bourdieu, entretanto, a maior limitação do chamado "programa forte", representado por Bloom, Barnes e Collins, reside no fato de que 
il reste enferme dans une vision interactionniste qui cherche dans les interactions entre les agents le principe de leurs actions et ignore les structures (ou les relations objectives) et les dispositions (le pus souvent corrélées avec la position occupée dans ces structures) qui sont le veritáble principe des actions et, entre autres choses, des interactions êllesmêmes (qui peuvent être la médiation entre les structures et les actions) (p. 46).

Ainda dentro da categoria "relativista" (e que se aproxima da perspectiva subjetivista aludida acima), ${ }^{11}$ em contraste com a categoria "logicista", representada pelos mertonianos (e que, por sua vez, aproxima-se do enfoque objetivista), Bourdieu refere-se aos trabalhos de Bruno Latour e Steve Woolgar, de acordo com os quais os produtos da ciência são o resultado dum processo de fabricação e o laboratório, universo artificial e isolado do mundo, é o lugar da construção ou mesmo da "criação" dos fenômenos. Latour e Woolgar, na avaliação bourdieusiana, querem com isso dizer que os fatos são fictícios, não objetivos, não autênticos. Sendo os fatos científicos construídos, comunicados e avaliados sob a forma de proposições escritas, o trabalho científico é essencialmente uma atividade literária e interpretativa. O semiologismo, por sua vez, combina-se com uma visão "ingenuamente maquiavélica" das estratégias dos estudiosos: as ações simbólicas que estes últimos perpetram para tornar reconhecidas suas "ficções" são, ao mesmo tempo, estratégias de influência e de poder pelos quais eles servem sua própria grandeza. Para Bourdieu, por não procurar o princípio das ações lá onde ele realmente está nas posições e nas disposições -, Latour não pode encontrá-lo senão nas estratégias conscientes e mesmo cínicas de influência e de poder, regressando assim dum finalismo dos coletivos à Merton a um finalismo dos agentes individuais.

Um dos pontos centrais que separa Bourdieu de todas as análises às quais ele se tem referido até agora e por meio do qual ele tenta superar os

\footnotetext{
${ }^{11} \mathrm{Na}$ verdade, essas várias formas de neo-wittgensteinismo se enquadram melhor no culturalismo textualista de Reckwitz, referido acima. Bourdieu, aliás, classifica sobretudo a abordagem de Latour e Woolgar de "textisme" (p. 59).
} 
dualismos estrutura/agência, objetivismo/subjetivismo e holismo/ individualismo é o conceito de campo. O campo científico, como os outros campos, é um campo de força, dotado duma estrutura, e um campo de lutas para conservar ou transformar esse campo de forças. Os agentes, estudiosos isolados, equipes ou laboratórios criam, por suas relações, o espaço mesmo que os determina, se bem que esse espaço não existe senão pelos agentes que nele se encontram posicionados, conferindo-lhe certa estrutura. São os agentes, definidos pelo volume e pela estrutura do capital específico que possuem, que determinam a estrutura do campo que os determina. O domínio duma quantidade importante de capital confere um poder sobre o campo e, conseqüentemente, sobre os agentes menos dotados de capital e comanda a distribuição das oportunidades de lucro. O dominante é aquele que ocupa na estrutura um lugar tal que a estrutura age em seu favor. Em linguagem que em muito pontos soa como a linguagem habermasia, Bourdieu seque afirmando que "les stratégies des chercheurs sont orientées par les constraintes et les possibilites objectives qui son inscrites dans leur position et par la représentation (elle-même liée à leur position) qu'ils peuvent se faire de leur position et de celle de leurs concurrents, en fonction de leur information et de leurs structures cognitives" (pp. 72-73). A margem de liberdade deixada às estratégias dependerá da estrutura do campo, caracterizada por um grau mais ou menos elevado de concentração de capital; mas essa estrutura se organizará sempre em torno da oposição principal entre os dominantes e os dominados ou desafiantes. Os primeiros detêm vantagens decisivas na competição, entre outras razões porque constituem ponto de referência obrigatório para seus concorrentes, que, seja lá o que façam ou queiram, são convocados a tomar posição em relação a eles, ativa ou passivamente. As ameaças que os desafiantes fazem pesar sobre eles obrigam-nos a uma vigilância constante e eles não podem manter sua posição senão por uma inovação permanente.

Em conformidade com Bourdieu, o campo científico é, como todos os outros campos, o lugar de lógicas práticas, mas com a diferença que o habitus científico é uma teoria realizada, incorporada. "Un savant est un champ scientifique fait homme", cujas estruturas cognitivas são homólogas à estrutura do campo e, desse fato, constantemente ajustadas às expectativas inscritas no campo. "Il serait sans doute vain de demander, dans ces conditions, où est la 
cause et où est l'effet et s'il est même possible de distinguer entre causes de l'action et les raisons d'agir"' (p. 84).

Para Bourdieu, o campo está submetido a pressões (exteriores) e habitado por tensões, entendidas como forças que agem de maneira a separar as partes dum corpo. Dizer que o campo é relativamente autônomo em relação ao universo social envolvente é dizer que o sistema de forças que são constitutivas da estrutura do campo (tensão) é relativamente independente das forças que se exercem sobre o campo (pressão). O processo de autonomização está ligado à elevação do direito de entrada. O direito de entrada é a competência, o capital científico incorporado, tornado senso do jogo, mas também a apetência, a libido scientifica, crença não somente nas regras do jogo, mas também no próprio jogo, no fato de que o jogo vale a pena ser jogado.

De acordo com Boudieu, o capital simbólico é um conjunto de propriedades distintivas que existem na e pela percepção de agentes dotados de categorias de percepção adequadas, categorias que se adquirem notadamente por meio da experiência da estrutura da distribuição desse capital no interior do espaço social ou dum microcosmo social particular como o campo científico. O capital científico, por sua vez, é um conjunto de propriedades que são produto de atos de conhecimento e reconhecimento realizados por agentes engajados no campo científico e dotados, por isso, de categorias de percepção específicas que lhe permitem fazer as distinções pertinentes, em conformidade com o princípio de pertinência constitutivo do nomos do campo. É, pois, produto do reconhecimento dos pares, o qual tende a produzir um efeito de fechamento. O conhecimento das propriedades pertinentes dum agente, de sua posição na estrutura de distribuição e de suas disposições, que estão mais freqüentemente correlacionadas com suas propriedades e com suas posições, permite prever (ou pelo menos compreender) suas tomadas de posição específicas. Isso porque a relação entre o espaço das posições e o espaço das tomadas de posição não é uma relação de reflexo mecânico: o espaço de posições não age sobre as tomadas de posição senão por intermédio dos habitus dos agentes que apreendem esse espaço, suas posições nesse espaço 
e a percepção que os outros agentes engajados nesse espaço têm do todo ou de parte desse espaço.

Se a análise sociológica do funcionamento do campo científico não condena a um relativismo radical, se se pode e se deve admitir que a ciência é um fato sócio-histórico sem com isso se concluir que suas produções estão limitadas às condições históricas e sociais de seu surgimento, argumenta Bourdieu, é porque o "sujeito" da ciência é não um coletivo integrado (como pensava Durkheim e a tradição mertoniana), mas um campo, e um campo singular, "dans lequel les rapports de force et de lutte entre les agents e les institutions son soumis aux lois spécifiques (dialogiques et argumentative)» (p. 138). A luta científica deve, assim, sua especificidade ao fato de que os concorrentes pelo monopólio da representação legítima da realidade objetiva dispõem dum equipamento coletivo de construção teórica e de verificação ou falsificação empírica, cujo domínio é exigido de todos os participantes da competição. A objetividade é, pois, um produto social do campo que depende de pressupostos aceitos nesse campo, notadamente no que concerne à maneira legítima de solucionar os conflitos. Em outras palavras, objetividade é intersubjetividade, é validação intersubjetiva. Na luta que arbitra o veredicto da experiência, é dizer, daquilo que os pesquisadores concordam em considerar como o real, a verdade é o conjunto de representações consideradas como verdadeiras por terem sido produzidas em conformidade com as regras que definem a produção da verdade. Daí que a versão de Gaston Bachelard do trabalho científico, resumida por Bourdieu, numa de suas primeiras obras (1968), na fórmula «Le fait scientifique est conquis, construit, constatés, é agora completada, de novo numa linguagem muito parecida com a de Habermas:

Le fait est conquis, construit, constaté dans et par la communication dialectique entre les sujets, c'est-à-dire à travers le processus de vérification, de production collective de la verité, dans et par la negotiation, la transaction et aussi l'homologation, ractification par le consensus explicitement exprimé homologein - (et non pas seulement dans la dialectique entre l'hypothèse et l'expérience) (2001, pp. 143-144). 
Portanto, conclui Bourdieu, é preciso rejeitar, dum lado, o absolutismo logicista e, doutro, o relativismo historicista. Em contrapartida, propõe uma démarche que, num primeiro momento, substitua as condições universais e os $a$ priori de Kant pelas condições e pelos a priori socialmente constituídos e, num segundo momento, realize o processo de historicização da interrogação kantiana numa objetivação científica do sujeito da objetivação, por meio do que denomina de

entreprise de reflexivité, visant à objectiver l'inconscient transcendental que le sujet connaissant investit sans le savoir dans ses actes de connaissance ou, si l'on veut, son habitus comme transcendental historique, dont on peut dire qu'il est a priori en tant que structure structurante qui organise la perception et l'appréciation de toute expérience et a posteriori en tant que structure structurée produite par toute une série d'apprentissages communs ou individuels (p. 154).

E, outra vez usando linguagem muito semelhante à utilizada por Habermas (inclusive citando textualmente uma conhecida expressão sua) e até mesmo reconhecendo expressamente a possibilidade de adequação da teoria habermasiana, Bourdieu assim arremata sua proposta de trabalho científico:

On peu sauver la raison sans invoquer, comme un Deus ex machina, telle ou telle forme de l'affirmation du caractère transcendental de la raison. Cela en décrivant l'émergence progressive d'univers dans lesquels pour avoir raison, il faut faire valoir des raisons, des démonstrations reconnues comme conséquentes, et où la logique des rapports de force et des luttes d'intérêt est ainsi réglée que la « force du meilleur argument» (dont parle Habermas) a des chances raisonnables de s'imposer. Les champs scientifiques sont des univers à l'intérieur desquels les rapports de force symboliques et des luttes d'intérêts qu'ils favorisent contribuent à donner sa force au meilleus argument (et à l'intérieu desquels la théorie de Habermas est vrai, à ceci 
près que'elle ne pose pas la question des conditions sociales de possibilité de ces univers et qu'elle inscrit cette possibilité dans des propriétés universelles du langage par une forme faussement historicisée de kantisme). ${ }^{12}$

Il existe donc des univers dans lesquels s'instaure un consensus social à propos de la verité mais qui sont soumis à des constraintes sociales favorisant l'échange rationnel et obéissant à des mecanismes d'universalisation tels que les contrôles mutuels (pp. 161-162).

\section{CONCLUSÃO}

Desde a publicação original de On the logic of social science em 1967, Habermas tem mudado de posição em pontos importantes. A idéia de fundar a investigação sócio-científica numa teoria da linguagem veio a dominar seu trabalho no final dos anos 1960s e início dos anos 1970s. No fim dos anos 1970s, ele iniciou a guinada que culminou em The theory of communicative action, guinada marcada pelo entendimento de que a metodologia e a epistemologia não são o caminho real para a teoria social. Antes, questões concernentes à lógica da investigação social somente podem ser frutíferas se tratadas em

\footnotetext{
${ }^{12}$ Até mesmo essas ressalvas que Bourdieu faz a Habermas não parecem resistir ao cotejo das grandes linhas de seus respectivos pensamentos, conforme representados nas obras em análise neste ensaio. Tais ruídos na comunicação entre os dois cientistas sociais, usando as expressões do próprio Bourdieu, parecem ser muito mais de caráter "sociológico" do que "lógico", parecem ser devidos mais a lutas entre eles visando a conquista de posições de legitimação no interior do campo das ciências sociais do que a problemas lógico-científicos intrínsecos (BOURDIEU, 1981).

${ }^{13}$ Habermas, pois, lança mão duma concepção dual de sociedade moderna: o "sistema da vida" e o "mundo da vida". A dimensão sistêmica é aquela em que se desenrolam as tarefas políticoadministrativas e de reprodução material da vida social. O "mundo da vida", por sua vez, é vislumbrado comum o cenário por excelência de processos de reprodução cultural, integração social, socialização e construção de identidades, todos eles lingüisticamente mediados. À medida que as sociedades se complexificam e se racionalizam, sistema e mundo da vida não só se desacoplam um em relação ao outro, mas também se diferenciam internamente. Os âmbitos sistêmicos se especializam em duas direções distintas: o Estado (poder) e o mercado (dinheiro).
} 
conexão com questões de substância. ${ }^{13} \mathrm{~A}$ despeito dessas mudanças ou desenvolvimentos, On the logic of social science mantém seu poder e fascinação, talvez por evitar o unilateralismo que ainda marca as teorias sociais contemporâneas e por, diferentemente destas, encontrar algo de valor na maioria das abordagens concorrentes, algo digno de ser preservado e reconstruído. Nesta obra, Habermas foi capaz de aproveitar insights desenvolvidos nas tradições fenomenológica (Schutz), etnometodológica (Garfinkel), lingüística (Wittgenstein) e hermenêutica (Gadamer) e, nessa base, construir um argumento que antecipou, em todos os pontos essenciais, os subseqüentes declínio do positivismo e surgimento do interpretativismo. Mas ele não parou por aí. Combateu, com a mesma intensidade, o outro extremo - o do "idealismo hermenêutico" -, que veio a alcançar como que uma contra-hegemonia na filosofia da ciência social (mas não, naturalmente, na prática da pesquisa social). Finalmente, Habermas encontra na psicanálise o mais sugestivo modelo para a reconceituação e a reintegração de elementos explicativos e compreensivos, funcionalistas e narrativos, necessários à teoria social. Antecipando sua discussão de Freud em Knowledge and human interests, publicado no ano seguinte, vê a teoria psicanalítica como um esquema interpretativo geral de desenvolvimento psicodinâmico, cuja aplicação na reconstrução narrativa das histórias de vida individuais demanda uma peculiar combinação de explicação causal e compreensão interpretativa.

Nos dois casos, prevalece a racionalidade instrumental (meios-fins) e os agentes são constrangidos por estruturas e regras impessoais. Já a racionalização do mundo da vida implica a marginalização e a fragmentação de concepções do mundo tradicional-religiosas em favor duma moral pós-convencional erguida sobre princípios altamente generalizados e abstratos. À medida que referências tradicionais e normativas se pulverizam, os processos de produção e reprodução cultural, de integração social e de construção de identidades passam a desenrolar-se a partir da racionalidade comunicativa e procedimental. Com isso, em condições ótimas, é a força do melhor argumento que tende a prevalecer, em detrimento de referências mágico-tradicionais.Para Habermas, está exatamente aqui o potencial emancipatório. Tais promessas emancipatórias, entretanto, vêem-se impedidas de realizar-se quando as esferas sociais sistêmicas ultrapassam seus limites de ação e passam a "colonizar o mundo da vida" (HABERMAS, 1984 e 1987; TAVOLARO, 2007). 
Science de la science et réflexivité (2001), diferentemente, foi publicado no final da vida e carreira de Bourdieu e, como alguns de seus trabalhos anteriores, concentra o foco no acesso reflexivo pelo ator a dimensões outrora inconscientes de seu próprio babitus. Neste e noutros trabalhos como o Homo academicus (1984), Bourdieu trata de casos de bysteresis, em que a ativação das condições encarnadas no habitus é exigida em contextos diferentes daqueles que o produziram e em que a conduta "natural-performativa" do habitus é substituída por motivações "hipotético-reflexivas" (os termos são de Habermas), estimulando assim a recuperação discursiva e a crítica explícita do que até então eram assunções doxicamente aceitas, isto é, a transmutação da práxis em logos. Outra tentativa de domínio reflexivo do próprio habitus ou de parte dele é feita pela própria sociologia da sociologia, caso em que ela pode assumir um papel emancipatório, notadamente quando submete ao escrutínio crítico disposições e esquemas interpretativos que levam os atores a perceberem como legítima (e, assim, a colaborarem, ainda que tacitamente, com) sua própria dominação. Cuida-se, aqui, de uma reatualização propriamente sociológica da noção kantiana de crítica. O procedimento da crítica em Bourdieu ainda une o sentido kantiano de escavação sistemática de pressupostos do pensamento e da ação ao sentido marxista de desvendamento de modalidades sóciohistóricas ideologicamente mascaradas de dominação e exploração. Por fim, a referência implícita na noção de sócio-análise desvela um enraizamento comum no projeto socrático da auto-consciência como caminho para a emancipação, é dizer, no propósito de expandir o nível da consciência humana para as dimensões determinantes de sua conduta, as quais, se deixadas intocadas por esse esforço reflexivo metodologicamente municiado, permanecem inconscientes, dissimuladas e reprimidas.

\footnotetext{
${ }^{14}$ De acordo com Axel Honneth (1986), discípulo de Habermas, Bourdieu nunca rompeu com a filosofia da consciência e com a teoria marxista do trabalho. Bourdieu (1984), por sua vez, entre outras críticas virulentas, acusa Habermas de ser um ideólogo que tira vantagens intelectuais do universalismo e de disfarçar "hipóteses metafísicas" em "declarações empíricas", bem como rotula sua teoria de "ilusão transcendental" e de "glorificação do diálogo racional".
} 
Vê-se, pois, notadamente no tocante ao problema da relação estrutura/ agência na teoria social, que há importantes pontos de convergência entre Habermas e Bourdieu, em que pese a um e outro, sobretudo Bourdieu, haverem enfatizado seus pontos de divergência. ${ }^{14} \mathrm{Com}$ efeito, não se poderá avançar na construção duma síntese capaz de articular o plano das estruturas coletivas com o plano da ação, essencial ao desenvolvimento da teoria social, a não ser que, como propôs o próprio Bourdieu (1981), rompendo-se com a facilidade e o conforto do encerramento numa tradição, faça-se com que "as teorias opostas se comuniquem". ${ }^{15}$

\section{REFERÊNCIAS BIBLIOGRÁFICAS}

BOUDIEU, Pierre et al. Le métier de sociologue: préalables épistémologiques. Paris: Mouton/École Pratique des Hautes Études en Sciences Sociales. 1968

Le sens pratique. Paris: Minuit, 1980.

- Questions de sociologie. Paris: Minuit, 1981.

. Homo academicus. Paris: Minuit, 1984.

- Raisons pratiques: sur la théorie de l'áction. Paris: Seuil, 1994.

Science de la science et réflexivité. Paris: Raisons d'agir, 2001.

HABERMAS, Jürgen. On the logic of the social sciences. Cambridge: The MIT Press, 1967.

\footnotetext{
15 Para Martins (2002), "num momento em que a perspectiva reinante nas ciências sociais tendia a opor de forma sistemática e quase religiosa as distintas tradições analíticas, procurando excluí-las mutuamente, Bourdieu incorporou em seu arcabouço teórico autores como Marx, Durkheim e Weber e dialogou, também de maneira heterodoxa e criativa, com diversos autores contemporâneos como Bachelard, Veblen, Lévi-Strauss, Elias, Goffman e Wittgenstein (...) Sua sociologia foi construída num denso e caloroso debate com as heranças do marxismo, funcionalismo, fenomenologia, interacionismo simbólico, individualismo metodológico etc.".
} 
. Knowledge and buman interests. Beacon Press, 1968.

. The theory of communicative action. Vol. 1: Reason and the rationalization of society. Boston: Beacon Press, 1984.

The theory of communicative action. Vol. 2: Lifeworld and system - a critique of functionalist reason. Boston: Beacon Press, 1987.

HONNETH, Axel. The Fragmented World of Symbolic Forms: Reflections on Pierre Bourdieu's Sociology of Culture. Theory, Culture \& Society, v. 3, p. 55-66. 1986.

MARTINS, Carlos Benedito. Notas sobre a noção prática em Pierre Bourdieu. Novos Estudos CEBRAP, n. 62, p. 163-181. 2002.

RECKWITZ, Andreas. Toward a theory of social practices: a development in culturalist theorizing. European Journal of Social Theory, v. 5 , n. 2, p. 243-263. 2002

TAVOLARO, Sérgio B. F. Variações no interior de um discurso hegemônico? Sobre a tensão "ação-estrutura" na sociologia contemporânea. Teoria \& Pesquisa, vol. 16, n. 1, p. 97-125. 2007 